Article

\title{
Hierarchically Nanostructured CuO-Cu Current Collector Fabricated by Hybrid Methods for Developed Li-Ion Batteries
}

\author{
Jin-Young So, Chan-Ho Lee ${ }^{\mathbb{D}}$, Ji-Eun Kim, Hyun-Jee Kim, Joonha Jun and Won-Gyu Bae * \\ Department of Electrical Engineering, Soongsil University, Seoul 156-743, Korea; igiyoun@ssu.ac.kr (J.-Y.S.); \\ chlee9306@gmail.com (C.-H.L.); wldms5103@gmail.com (J.-E.K.); qmffptmb@gmail.com (H.-J.K.); \\ joonha9974@gmail.com (J.J.) \\ * Correspondence: wgbae@ssu.ac.kr; Tel.: +82-2-820-0655
}

Received: 2 May 2018; Accepted: 12 June 2018; Published: 15 June 2018

\begin{abstract}
We present a simple method of fabricating a hierarchically nanostructured $\mathrm{CuO}-\mathrm{Cu}$ current collector by using laser ablation and metal mold imprinting to maximize the surface area. The laser ablation of the $\mathrm{Cu}$ current collector created the $\mathrm{CuO}$ nanostructure on the $\mathrm{Cu}$-collector surface. The microstructure was transferred by subsequent imprinting of the microstructure metal mold on the $\mathrm{Cu}$ collector. Then, the laser-ablation nanostructure was formed. Consequently, a hierarchical structure is generated. The laser-ablated hierarchical $\mathrm{CuO}-\mathrm{Cu}$ current collector exhibited an improved capacity while maintaining a cyclability that is similar to those of conventional graphite batteries.
\end{abstract}

Keywords: hierarchical current collector; laser ablation; oxidation; $\mathrm{CuO}$; imprinting

\section{Introduction}

With the rapid development of technology, the demand for various mobile electronic products such as cell phones, tablets, and smart healthcare devices has increased explosively [1-3], and studies with the aim of developing lithium-ion batteries (LIB) of a high efficiency, stability, and low cost have been actively conducted. Graphite $\left(372 \mathrm{mAh} \mathrm{g}^{-1}\right)$ [4] has been used as the anode material in the fabrication of Li-ion batteries with a low theoretical capacity, because the anode material directly affects the capacity of Li-ion batteries. Although silicon-based material is emerging as an ideal replacement for the commercial carbonaceous material owing to its highest theoretical capacity $\left(4200 \mathrm{mAh} \mathrm{g}^{-1}\right)$, it would be difficult to replace that because of the volume expansion of the silicon-based anode during the charge/discharge process. Innovative silicon nanostructures, therefore, have been used in numerous studies in order to prevent volume expansion of Si-based anodes (i.e., nanoparticles [5,6], nanowires [7], and nanotubes [8]). Despite the important achievements mentioned, poisonous and dangerous reagents are not appropriate in a synthesis process. When sophisticated equipment is necessary or expensive and multi-stage synthesis is adopted, it is not easy to increase the scale. Accordingly, there still remain significant challenges to overcome the commercialization of the Si anode.

In the case of transition metal oxides, the capacity is much higher than the capacity of the graphitic carbon, and the volume change is not as great as the silicon material. Therefore, the use of a transition metal oxide as the anode material appears to be an appropriate way to overcome the drawbacks of the alloy anode material [9]. Copper $(\mathrm{Cu})$-based oxides such as copper $\left(\mathrm{Cu}_{2} \mathrm{O}\right)$ and copper $(\mathrm{CuO})$ oxides, as well as transition metal oxides, are under the spotlight for promising candidates for use in LIB, solar cells, supercapacitors, gas sensors, biosensors and catalysts due to their inherent properties as p-type semiconductors with a low band gap energy, high optical absorption and high catalytic activity.

Cupric oxide $(\mathrm{CuO})$ [10] and cuprous oxide $\left(\mathrm{Cu}_{2} \mathrm{O}\right)$ [11], with the respective capacities of $674 \mathrm{mAh} \mathrm{g}^{-1}$ and $375 \mathrm{mAh} \mathrm{g}^{-1}$, have received enormous attention owing to high theoretical capacities, 
low costs, non-toxicity, and abundant natural reserves. Alternatively, regarding the LIB for which $\mathrm{CuO}$ and $\mathrm{Cu}_{2} \mathrm{O}$ serve as the anode materials, the generation of very large volume expansions occurs during the battery lithiation and delithiation processes, resulting in not only a separation from the copper $(\mathrm{Cu})$ current collector, but a poor cyclability, low capacity, and low electronic conductivity $[12,13]$. To solve these problems, numerous studies have been conducted to mitigate the volume-expansion stress, where the anode material nanostructure has been fabricated into nanoparticles, nanowires, nanotubes, nanorods and nanoflake structures [14-17]. Notwithstanding the significant improvements in the electrochemical performance of the Li-ion batteries that are enabled by these studies, the corresponding methods require exorbitant devices, complicated preparations, and time-consuming tasks, and difficulties of low-cost large-area processing are encountered as well.

Meanwhile, fabrication of nanostructured metal oxides generated on the metal substrates by fast pulsed laser ablation has been reported. A series of nanostructured metal oxides have been synthesized by pulsed laser ablation of metal substrates.

Here, graphite, the anode material of the conventional battery, was replaced with $\mathrm{CuO}$ through the formation of $\mathrm{CuO}$ on the $\mathrm{Cu}$ surface that was achieved by a simple, fast, innocuous, and inexpensive laser irradiation of the $\mathrm{Cu}$ current collector; nanostructures, which were made through laser ablation, prevented the degradation of the battery capacity and cyclability that are results of the volume expansion. The laser ablation spontaneously allowed the formation of the nanostructure on the $\mathrm{Cu}$ current collector. Then, the microstructure was transferred onto the $\mathrm{Cu}$ current collector through the imprinting of the microstructural metal mold on the $\mathrm{Cu}$ current collector, wherein the nanostructure was formed. This process was carried out considering the use of a hierarchical structure [18] consisting of both the nano- and microstructures, which accommodate volume expansion of Si more than solely the nanostructure. The lithium-ion battery that is based on the hierarchically nanostructured $\mathrm{CuO}-\mathrm{Cu}$ current collector with the micro- and nanostructures not only maintained a cyclability that is similar to those of the conventional types, but the capacity was improved twofold. The proposed method of this paper can be directly applied to the existing battery-fabrication process, as laser ablation enables an increase in the battery capacity via a chemical-free process in a fast and simple manner.

\section{Materials and Methods}

\subsection{Laser Ablation}

A single-mode HY-FM20 nanosecond (ns) pulsed laser with output powers of 10, 20, and $30 \mathrm{~W}$ at room temperature and in air was used in this study to create the multiscale structure on the surface of the $\mathrm{Cu}$ current collector. The laser beam of the YLP-V2-model HY-FM20 laser source (IPG Lasers, Burbach, Germany) generates a central-emission wavelength of $1064 \mathrm{~nm}$, and the maximum pulse-repetition rate of $1000 \mathrm{kHz}$ was delivered by a total of three reflective mirrors, a beam expander, an $x$ - and $y$-axes galvanometer scanner, and a telocentric focusing lens. Moreover, the beam-spot size at the focal point was approximately $10 \mu \mathrm{m}$. The sample movement was generated by an $x-/ y$-/z-axes movable stage with the ball-screw mechanism. The nanosecond laser was used to ablate over the $\mathrm{Cu}$ current collector $(30 \mathrm{~mm} \times 30 \mathrm{~mm})$ at the working speed of $2000 \mathrm{~mm} / \mathrm{s}$, the width of $0.01 \mathrm{~mm}$, the moving speed of $500 \mathrm{~mm} / \mathrm{min}$, and the power of $100 \mathrm{~W}$.

\subsection{Metal Mold}

The metal mold (30-mm length $\times 30$-mm width $\times 2$-mm thickness) with the line-pattern $(500-\mu \mathrm{m}$ wavelength) was fabricated using wire electrical discharge machining (WEDM) with a precision process. The WEDM process was used to process the master metal mold, the rigidity of which was high. For the WEDM process that was used in the metal precision processing, a method to apply a square-wave alternating current (ac) voltage between the wire electrode and the workpiece was employed [19]. In the present study, the master-mold surface was cut using electrical-discharge energy via the positive voltage of $+126 \mathrm{~V}$, the negative voltage of $-80 \mathrm{~V}$, the positive duration of $28 \mu \mathrm{s}$, and the 
negative duration of $50 \mu \mathrm{s}$, for which the commercial EZ20S WEDM machine (Seoul Precision Machine, Seoul, Korea) was employed.

\subsection{Imprinting Process}

The pattern of the fabricated metal mold was transferred to $\mathrm{Cu}$ foils (Hohsen Corporation, Osaka, Japan) that subsequently served as current collectors using the imprinting process [20]. The imprinting process was performed by pressing the patterned metal mold onto the $\mathrm{Cu}$ foils under a pressure of $10 \mathrm{MPa}$ for $5 \mathrm{~min}$.

\subsection{Electrochemical Measurements}

A scanning electron microscope (SEM)-electrochemical dispersive spectroscopy (EDS) investigation was carried out using the JSM 5900 SEM (JEOL, Tokyo, Japan) equipped with the X-ray-microanalysis Oxford-ISIS EDS (Oxford Instruments, Oxford, UK) that comprises the silicon (lithium) detector. The electron-beam voltage for the observation was between $5 \mathrm{kV}$ and $20 \mathrm{kV}$ and its current is between $0.01 \mathrm{nA}$ and $10 \mathrm{nA}$. The samples were analyzed using the EDS instrument under a low vacuum, and with the working distance of $10 \mathrm{~mm}$, the beam voltage of $20 \mathrm{kV}$, and the current of $0.25 \mathrm{nA}$.

Electron probe microanalysis (EPMA)-wavelength dispersive spectroscopy (WDS) maps were derived using the JXA 8800 R SUPER PROBE electron microprobe (JEOL, Tokyo, Japan) equipped with four spectrometers. The electron-beam voltage was $15 \mathrm{kV}$ and the current was $40 \mathrm{nA}$. Cu, carbon, and oxygen maps were performed using the sample, and the maps were obtained with sets of $300 \times 300$ spots on areas of approximately $600 \times 600 \mu \mathrm{m}^{2}$. In every map, each color represented the corresponding element, and every color was independent of the other colors.

\subsection{Electrochemical Properties of Graphite and $\mathrm{CuO}$ Electrodes}

The electrochemical properties of the anode electrodes were evaluated using size-2032 coin-type cells (Hohsen Corp., Osaka, Japan). The cell assembly was carried out in an argon (Ar)-filled glove box ( $<5 \mathrm{ppm}$ of $\mathrm{H}_{2} \mathrm{O}$ and $\mathrm{O}_{2}$ ). The as-prepared anode electrodes, cut with a diameter of $13 \Phi$, and lithium foil, were used as the working and counter electrodes, respectively. Celgard 2400 porous polyethylene (Celgard, Cheongju-Si Chungbuk, Korea) and 1.1-M lithiumhexafluorophosphate $\left(\mathrm{LiPF}_{6}\right)$ dissolved in ethylene carbonate (EC):dimethyl carbonate (DEC) of a 1:1 vol \% were used as the separator and the electrolyte, respectively. The charge-discharge characteristic curves of the assembled cells were obtained using the WBCS3000L multichannel battery tester (WonATech, Seoul, Korea) at $25^{\circ} \mathrm{C}$. Electrochemical impedance spectroscopy (EIS) was performed using the Eco Chemie electrochemical analyzer (Metrohm, Utrecht, The Netherlands) at the applied voltage of $5 \mathrm{mV}$ in the frequency range of $10-100 \mathrm{kHz}$.

\section{Results and Discussion}

Figure 1 illustrates the overall fabrication process of the hierarchically nanostructured $\mathrm{CuO}-\mathrm{Cu}$ current collector and its application in the design of the lithium-ion battery. The first step, as shown in Figure $1 \mathrm{a}$, represents the nanosecond laser ablation on the $\mathrm{Cu}$ current collector; The surface of the $\mathrm{Cu}$ collector in the laser-cutting process was immediately vaporized by high energy and thermal laser pulses. The avalanche ionization induced by the intense laser field excited the copper vapor to the plasma. Plasma and/or superfine $\mathrm{Cu}$ particles were then oxidized in air and deposited on the surface of the $\mathrm{Cu}$ current collector substrate and cooled to room temperature within a very short time. Finally, due to the very high pressure of the atmospheric atmosphere in which the superfine particles were generated, a uniformly distributed faulty $\mathrm{CuO}$ hierarchical nanostructure which was firmly adhered to the surface of the $\mathrm{Cu}$ current collector after the $\mathrm{CuO}$ particles retracted onto the substrate. The $\mathrm{Cu}$ was evaporated by the heat generated and converted into $\mathrm{CuO}$ through the two-step oxidation of $4 \mathrm{Cu}+$ $\mathrm{O}_{2} \rightarrow 2 \mathrm{Cu}_{2} \mathrm{O}, 2 \mathrm{Cu}_{2} \mathrm{O}+\mathrm{O}_{2} \rightarrow 4 \mathrm{CuO}$ in air [21]. 
(a)

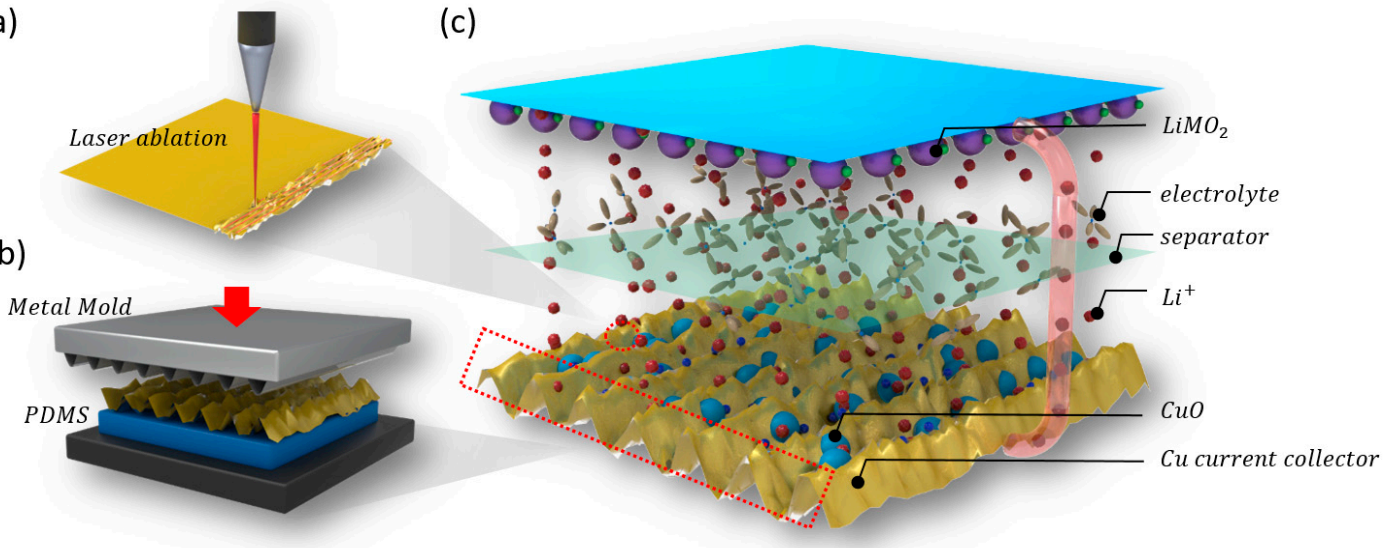

Figure 1. Fabrication of the hierarchically nanostructured $\mathrm{CuO}-\mathrm{Cu}$ current collector: (a) $\mathrm{CuO}-\mathrm{Cu}$ current collector with the nanostructure formed from the laser ablation on the $\mathrm{Cu}$ current collector; (b) imprinting method over the $\mathrm{CuO}-\mathrm{Cu}$ current collector for the microstructure addition; (c) lithium-ion battery for which the hierarchically nanostructured $\mathrm{CuO}-\mathrm{Cu}$ current collector was applied.

The second step of Figure $1 \mathrm{~b}$ shows the imprinting of the line-patterned metal mold on the $\mathrm{Cu}$ current collector with the nanostructure constructed by the laser ablation. The sinusoidal pathway of the proposed line-patterned metal mold obtained the 500- $\mu \mathrm{m}$ wavelength. Then, the Cu current collector in which the nanostructure was formed was placed on polydimethylsiloxane (PDMS), and the line pattern was transferred onto the $\mathrm{Cu}$ current collector using imprinting by the generated line-patterned metal mold (under the pressure of $10 \mathrm{MPa}$ for $5 \mathrm{~min}$ ). The PDMS served as the buffer layer and allowed the microsize line pattern to be properly transferred to the $\mathrm{Cu}$ current collector while the ablation-produced nanostructure was entirely maintained. The $\mathrm{CuO}-\mathrm{Cu}$ current collector was consequently fabricated with a hierarchical structure that is frequently used to broaden the surface area in nature.

The last step, shown in Figure 1c, is the demonstration of the application of the hierarchically nanostructured $\mathrm{CuO}-\mathrm{Cu}$ current collector, which replaced the conventional $\mathrm{Cu}$ current collector and the graphite anode material, in the design of the lithium-ion battery. The cycling-performance test was subsequently carried out.

Figure 2 shows the EPMA and EDS chemical analyses regarding the $\mathrm{CuO}-\mathrm{Cu}$ current collector, which was formed as a result of the laser ablation on the bare $\mathrm{Cu}$ current collector. In Figure 2a, the top sections of each of the EPMA images indicate the regions on the bare $\mathrm{Cu}$ current collector under the $50-\mathrm{W}$ and $100-\mathrm{W}$ ablation powers. As the analysis data of the bare $\mathrm{Cu}$ current collector show, at the top of the image the oxygen component of the pink region appears to be low, and then it gradually increases further down the image; that is, as the $\mathrm{Cu}$ current collector was oxidized by the laser's high energy and heat, the $\mathrm{CuO}$ became evenly generated on the surface. The EDS numerical-analysis data are shown in Figure $2 b$, where the graph indicates the relative contents of $\mathrm{Cu}, \mathrm{C}$, and $\mathrm{O}_{2}$ as quantitative materials; moreover, the inset graph, an enlargement of the $\mathrm{C}$ and $\mathrm{O}_{2}$ results, demonstrates that the bare $\mathrm{Cu}$ current collector consisting of $97.80 \%$ of $\mathrm{Cu}$ and $0.22 \%$ of $\mathrm{O}_{2}$ represents significantly lower oxygen content compared with the $\mathrm{Cu}$ content. Alternatively, the $\mathrm{Cu}$ current collector at $100 \mathrm{~W}$ comprising $96.94 \%$ of $\mathrm{Cu}$ and $0.81 \%$ of $\mathrm{O}_{2}$ is the result of the state at $50 \mathrm{~W}$ consisting of $96.09 \%$ of $\mathrm{Cu}$ and $1.55 \%$ of $\mathrm{O}_{2}$, respectively, and this presents the rapid $\mathrm{O}$ increase. This result shows the combining of the $\mathrm{Cu}$ and $\mathrm{O}_{2}$ in the air and the subsequent deposition of this combination on the surface that increased the oxygen floating on the surface. The $\mathrm{Cu}$ current collector that was ablated with the 100-W laser was used in the subsequent experiments, where the efficiency was increased as the $\mathrm{CuO}$ content grew. Furthermore, Figure 2 shows that laser ablation can quickly and simply produce $\mathrm{CuO}$ with a 
high theoretical capacity without any chemical treatment, and a higher capacity that outperforms the conventional lithium-ion battery is anticipated.

(a)
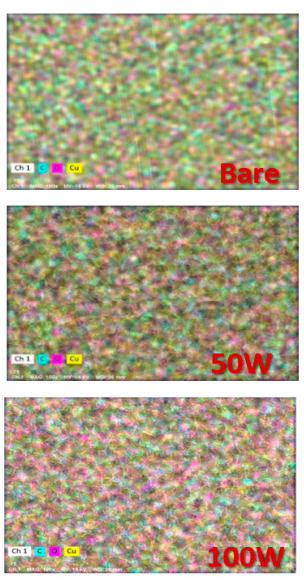

(b)

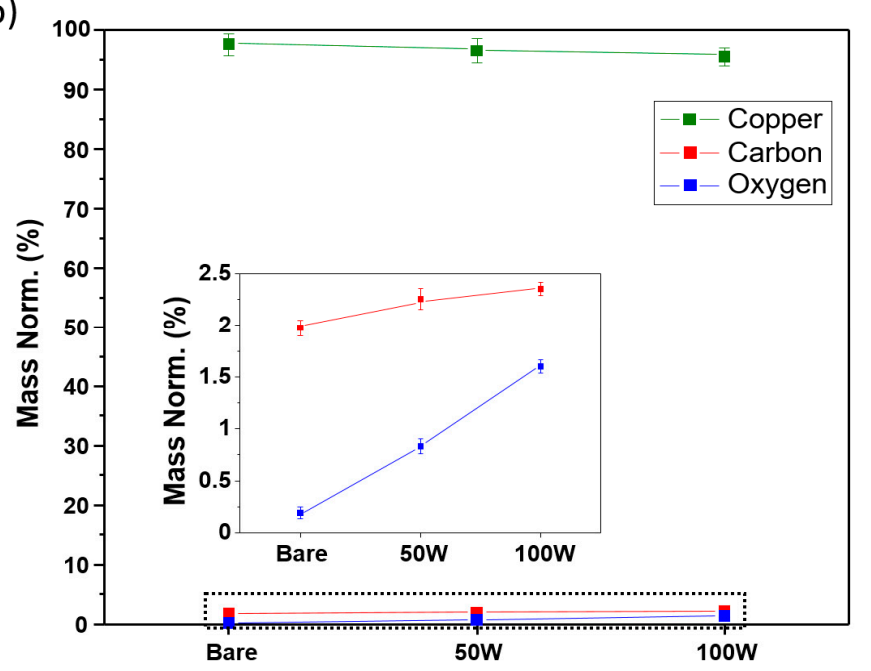

Figure 2. Electron probe microanalyzer (EPMA) and electron dispersive spectroscopy (EDS) data of copper, carbon, and oxygen on the $\mathrm{Cu}$ current collector after the laser ablations of $50 \mathrm{~W}$ and $100 \mathrm{~W}$ : (a) EPMA map; (b) EDS analysis.

SEM $(500 \times)$ images of the bare $\mathrm{Cu}$ current collector, laser-ablated $\mathrm{Cu}$ current collector, imprinted $\mathrm{Cu}$ current collector, and laser + imprinted $\mathrm{Cu}$ current collector are represented in Figure 3a-d, respectively. A flat surface is seen in Figure 3a, while in Figure $3 b$, the surface becomes very rough due to the explosion of the laser energy. Figure $3 c$ shows the illustration of the sinusoidal pathway of the $\mathrm{Cu}$ current collector of the $500-\mu \mathrm{m}$ wavelength that was constructed using the imprinting process. Figure $3 \mathrm{~d}$ shows the laser-ablated nanostructure and the combined-hierarchy $\mathrm{Cu}$ current collector with the microstructure that was formed using metal-mold imprinting.

(a)

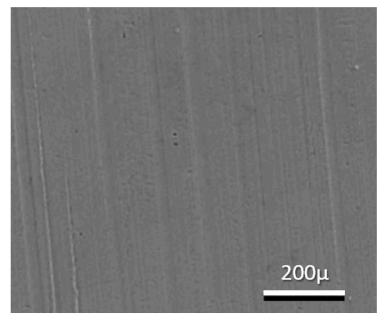

(c)

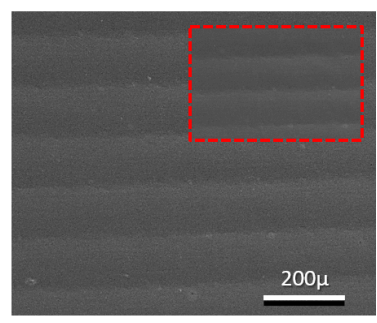

(b)

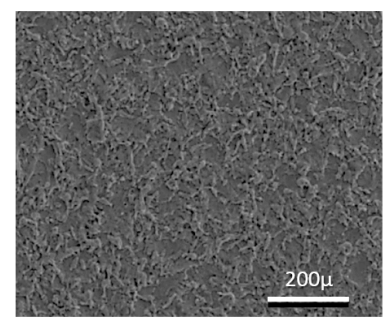

(d)

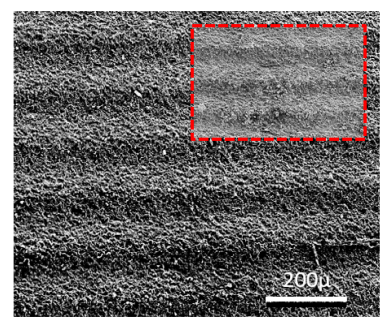

Figure 3. Scanning electron microscope (SEM) images of four samples of the $\mathrm{Cu}$ current collector: (a) bare $\mathrm{Cu}$ current collector; (b) laser-ablated $\mathrm{Cu}$ current collector; (c) imprinted Cu current collector; (d) laser + imprinted $\mathrm{Cu}$ current collector. 
Figure $4 a, d, g, j$ respectively show the three-dimensional (3D) surface-analysis images of the four types of the fabricated $\mathrm{Cu}$ current collector, as follows: bare $\mathrm{Cu}$ current collector, laser-ablated $\mathrm{Cu}$ current collector, imprinted $\mathrm{Cu}$ current collector, and laser + imprinted $\mathrm{Cu}$ current collector. The figure shows that 3D images provide results that are the same as those of Figure 3. The line-scan profiles of the bare $\mathrm{Cu}$ current collector, laser-ablated $\mathrm{Cu}$ current collector, imprinted $\mathrm{Cu}$ current collector, and laser + imprinted $\mathrm{Cu}$ current collector, measured using the non-contact 3D microtiter, are shown in Figure $4 \mathrm{~b}, \mathrm{e}, \mathrm{h}, \mathrm{k}$, respectively. The graphs above and below show the line-scan profiles of the Cu current collectors that were extracted at three different spots along the $x$ - and $y$-axes, respectively. The line-scan profile indicates the elevation of the surface relative to zero. Also, the greater the amount of ripples, the rougher the surface and the wider the surface area; these results also indicate that the surface is flat, which is shown by the $x$ - and $y$-axes on the line-scan profiles where only straight lines are apparent.

(a)

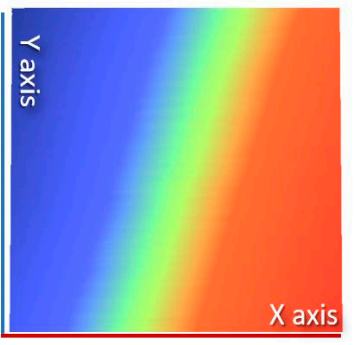

(d)

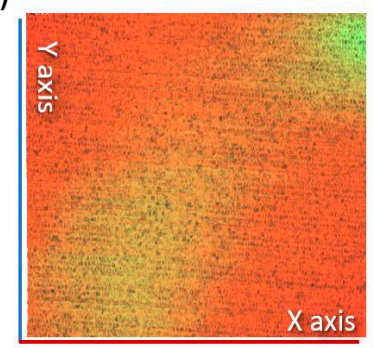

(g)

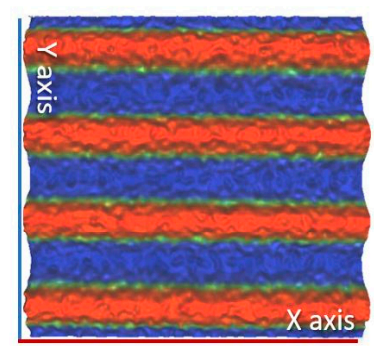

(j)

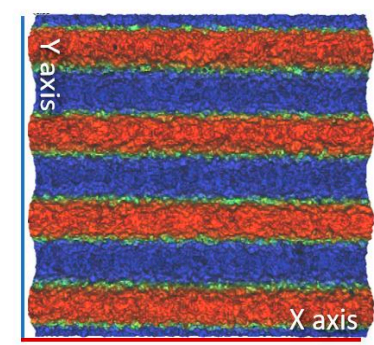

(b)
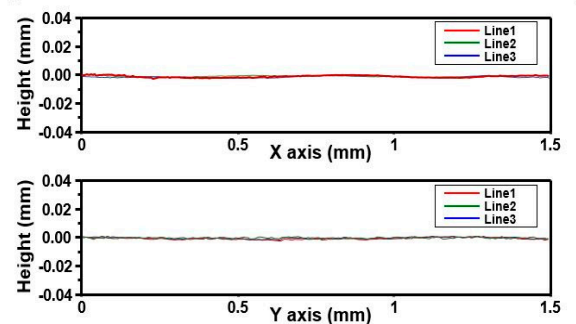

(e)
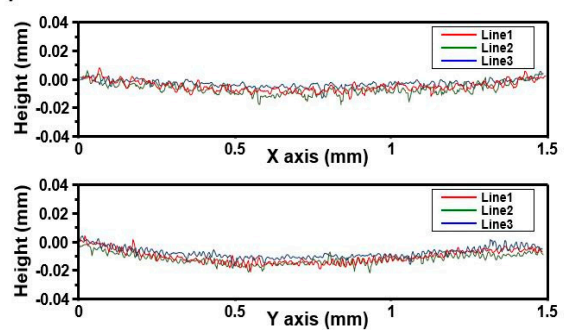

(h)
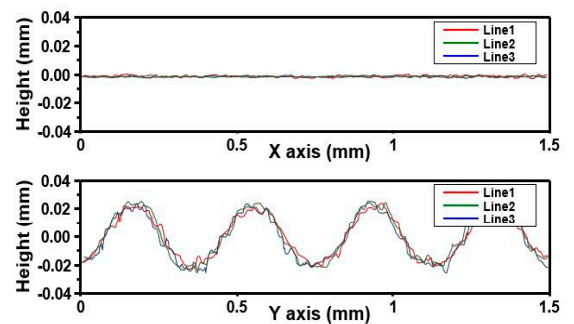

(k)

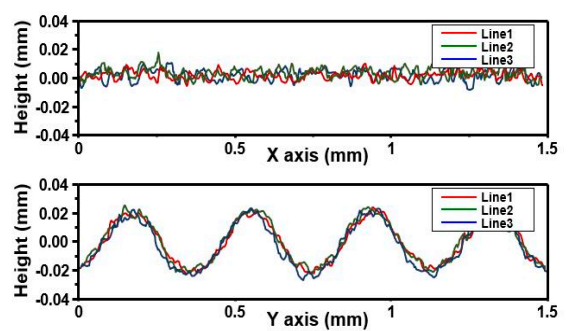

(c)

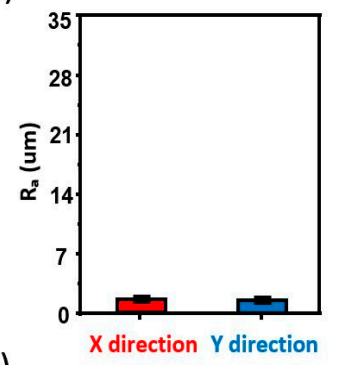

(f)

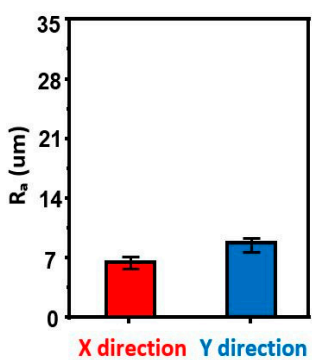

(i)

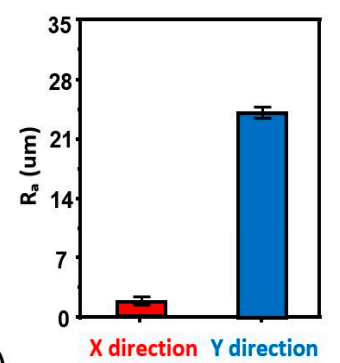

(I)

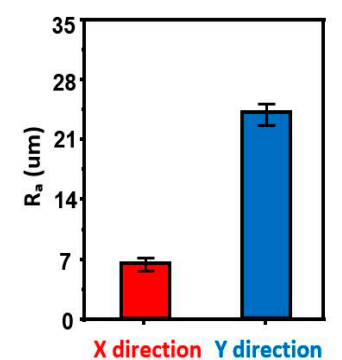

Figure 4. Three-dimensional (3D) image: $(\mathbf{a}, \mathbf{d}, \mathbf{g}, \mathbf{j})$; line-scan profiles in the $x$ and $y$ directions: $(\mathbf{b}, \mathbf{e}, \mathbf{h}, \mathbf{k})$; surface-roughness averages $\left(\mathrm{R}_{\mathrm{a}}\right)$ : $(\mathbf{c}, \mathbf{f}, \mathbf{i}, \mathbf{l})$. form above the first row, bare $\mathrm{Cu}$ current collector, $\mathrm{Cu}$ current collector after the laser ablation (laser-ablated $\mathrm{Cu}$ current collector), $\mathrm{Cu}$ current collector after the imprinting metal mold, and $\mathrm{Cu}$ current collector after the laser ablation + imprinting sequentially. 
Moreover, as illustrated in Figure 4e, the line-scan profile comprises many ripples on the $x$ and $y$-axes relative to zero. Accordingly, the surface area per unit area of the proposed $\mathrm{Cu}$ current collector became larger than that of the bare $\mathrm{Cu}$ current collector due to the spontaneously generated laser-ablation ripple. From the line-scan profile of Figure $4 \mathrm{~h}$, the $500-\mu \mathrm{m}$ wavelength occurred periodically, thereby resulting in an effectively performed transfer of the metal-mold pattern and the incremental transfer of the surface area per unit area compared with the bare $\mathrm{Cu}$ current collector. Figure $4 k$, in contrast, shows the line-scan profile with numerous ripples and periodic appearances of the $\mu \mathrm{m}$ wavelengths that are owing to the simultaneously presented laser-ablation nanostructure and the metal-mold microstructure. This result represents a nanostructure that is not affected by the imprinting, a well-transferred microstructure, and a hierarchical structure that became the widest surface area per unit area.

Quantitative evaluation was performed to compare the increase of the surface area accurately. Figure $4 \mathrm{c}, \mathrm{f}, \mathrm{i}, \mathrm{l}$ show the surface-roughness averages $\left(\mathrm{R}_{\mathrm{a}}\right)$ of the bare $\mathrm{Cu}$ current collector, laser-ablated $\mathrm{Cu}$ current collector, imprinted $\mathrm{Cu}$ current collector, and laser + imprinted $\mathrm{Cu}$ current collector, respectively. The $R_{a}$ values indicate the degree of the surface roughness, where the value increases with the increasing roughness of the surface; that is, the incremental increase of the $R_{a}$ value compared with the previous value means that the surface area per unit area has increased [22]. Furthermore, the bar values along the $x$ - and $y$-axes and the standard error demonstrate the mean and the standard deviation of the red, green, and blue along the $x$ - and $y$-axes of the line-scan profiles shown in Figure $4 \mathrm{~b}, \mathrm{e}, \mathrm{h}, \mathrm{k}$. The $R_{a}$ values of the $x$ - and $y$-axes in Figure $4 \mathrm{c}$ are 1.73 and 1.72, respectively. Compared with Figure $4 \mathrm{c}, \mathrm{f}$ shows increases of the $\mathrm{R}_{\mathrm{a}}$ values of the $x$ - and $y$-axes (6.63 and 8.72) by $383 \%$ and $506 \%$, respectively, thereby quantitatively confirming an enormous increase of the surface area. In Figure $4 i$, the $R_{a}$ values of the $x$ - and $y$-axes are 1.76 and 21.7, respectively, while the $\mathrm{R}_{\mathrm{a}}$ value of the $x$-axis is similar to that of Figure $4 \mathrm{c}$ and the $y$-axis was increased by $1261 \%$. As shown in Figure $4 \mathrm{i}$, the $\mathrm{R}_{\mathrm{a}}$ values of the $x$ and $y$-axes are 6.52 and 24.4, respectively. Here, the figures suggest that the surface area per unit area among the samples increased the most due to the increase of the $\mathrm{R}_{\mathrm{a}}$ values of the $x$ - and $y$-axes by $376 \%$ and $1418 \%$, respectively, compared with Figure $4 c$. The results of Figures 3 and 4 provide the optimal method for maximizing the surface area for which the hierarchically nanostructured structures were used.

Figure 5 shows the charge-discharge curves of the lithium-ion batteries that were prepared using the bare $\mathrm{Cu}$ current collector, laser-ablated $\mathrm{Cu}$ current collector, imprinted $\mathrm{Cu}$ current collector, and laser + imprinted $\mathrm{Cu}$ current collector. Graphite was used as the anode material of the bare $\mathrm{Cu}$ current collector and the imprinted $\mathrm{Cu}$ current collector. Alternatively, $\mathrm{CuO}$, deposited on the surfaces of the laser-ablated $\mathrm{Cu}$ current collector and the laser + imprinted $\mathrm{Cu}$ current collector as the product of the laser oxidation of the $\mathrm{Cu}$ current collector, was used as the anode material. The charging and discharging were carried out at the current density of $6 \mathrm{~A} \mathrm{~g}^{-1}$ in the range of $0.01-1.50 \mathrm{~V}$.

Figure 5a shows the charge-discharge curves of the lithium-ion battery of the bare $\mathrm{Cu}$ current collector. The capacity after 100 cycles is $203 \mathrm{mAh} \mathrm{g}^{-1}$. The initial coulombic efficiency (CE) of Figure 5 a was maintained at $98 \%$ after 25 cycles, where the CE signifies the battery efficiency [23]. Figure $5 \mathrm{~b}$ illustrates the charge-discharge curves of the lithium-ion battery of the laser-ablated $\mathrm{Cu}$ current collector. The capacity after 100 cycles is $343 \mathrm{mAh} \mathrm{g}^{-1}$. The CE was maintained at $92 \%$ after 25 cycles. The capacity after 100 cycles increased by $168 \%$, and the CE was analogously maintained in comparison with Figure $5 \mathrm{a}$; this is because the capacity was increased as $\mathrm{CuO}$, which was formed by the laser ablation, was used as the anode material. Moreover, the nanostructure, which was constructed by the laser ablation, created a void space. The void space not only provides space for $\mathrm{CuO}$ to accommodate the volumetric expansion during charging and discharging, but it also enlarges the surface area so that the increased interatomic attraction force enables the effective adherence between $\mathrm{CuO}$ and the $\mathrm{Cu}$ current collector; this leads to an improved conductivity and helps to improve the capacity as well. Figure $5 \mathrm{c}$ shows the charge-discharge curves of the lithium-ion battery of the imprinted $\mathrm{Cu}$ current collector. The capacity after 100 cycles is $241 \mathrm{mAh} \mathrm{g}^{-1}$. The CE was 
maintained at $95 \%$ after 25 cycles. The capacity after 100 cycles increased slightly by $119 \%$ compared with Figure 5a. This finding is because of the unaltered theoretical capacity that is due to the use of the same anode material, graphite, but also since the microstructural sinusoidal pathway increases the surface area, which may provide the positive impacts as it expands the surface area where graphite and lithium react. Therefore, the imprinted $\mathrm{Cu}$ current collector has better conductivity than the bare $\mathrm{Cu}$ current collector. Figure $5 \mathrm{~d}$ demonstrates the charge-discharge curves of the lithium-ion battery of the laser + imprinted Cu current collector. The capacity after 100 cycles is $392 \mathrm{mAh} \mathrm{g}^{-1}$. The CE was maintained at $94 \%$ after 25 cycles. The capacity after 100 cycles was increased by $193 \%$ compared with Figure $5 \mathrm{a}$, and the $\mathrm{CE}$ is analogous to Figure $4 \mathrm{c}$. In comparison with the other samples, the capacity after 100 cycles is the highest. This finding is because of the micro and nano mixed structures that are used to increase the surface area in nature; that is, the surface area became the widest among the samples, thereby leading to the reduced separation between $\mathrm{CuO}$ and the $\mathrm{Cu}$ current collector that is due to the highest increase of the interatomic attraction.

(a)

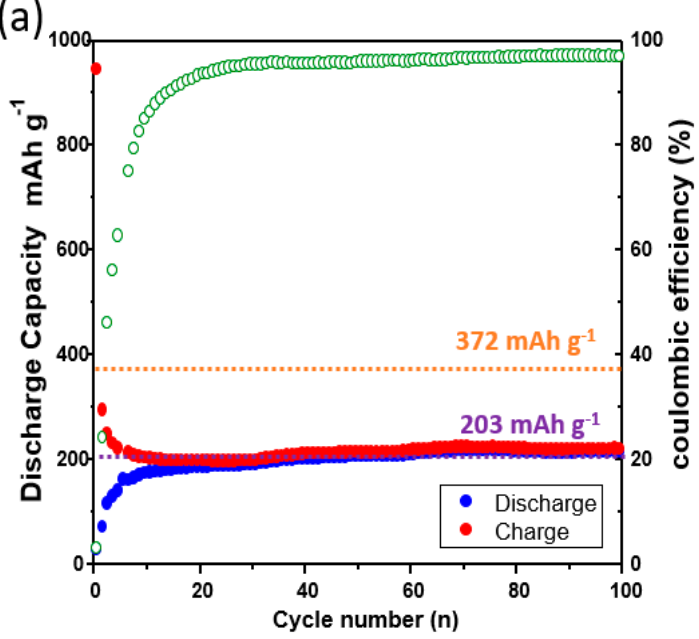

(c)

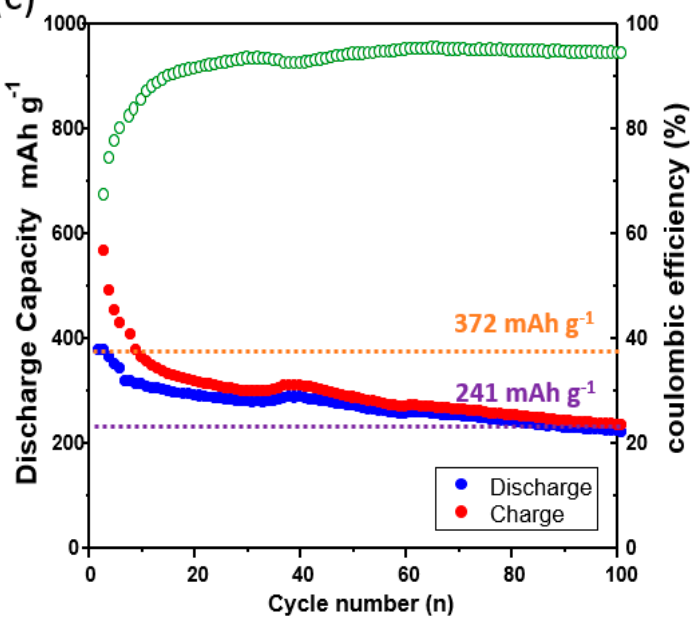

(b)

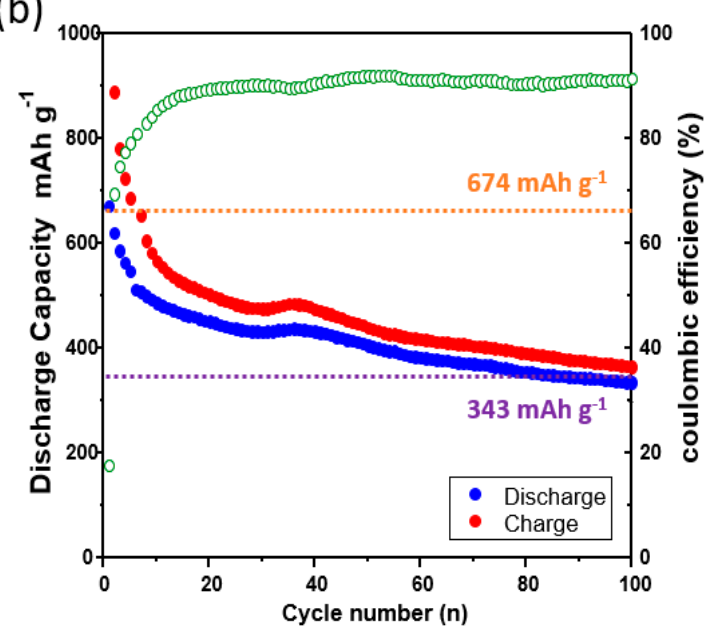

(d)

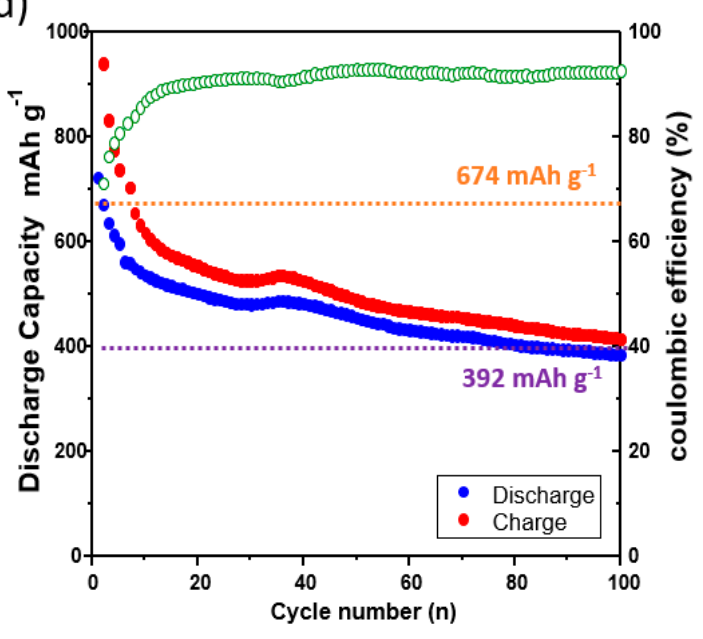

Figure 5. Charge-discharge graphs of the use of the four samples of the $\mathrm{Cu}$ current collector for the lithium-ion battery (orange dashed line: theoretical capacity, yellow dashed line: capacity after 100 cycles): (a) the charge-discharge curves of the bare $\mathrm{Cu}$ current collector when graphite is deposited on the current collector; (b) the charge-discharge curves of the $\mathrm{CuO}$ (the product of the oxidation of the $\mathrm{Cu}$ current collector by the laser)-deposited $\mathrm{Cu}$ current collector irradiated with the laser; (c) the charge-discharge curves of the graphite-deposited $\mathrm{Cu}$ current collector imprinted with the microstructure metal mold; (d) the charge-discharge curves of the $\mathrm{CuO}$ (the product of the oxidation of the $\mathrm{Cu}$ current collector by the laser)-deposited $\mathrm{Cu}$ current collector irradiated with the laser and imprinted with the microstructure metal mold. 


\section{Conclusions}

This paper presents the proposal of a simple method for the fabrication of a hierarchically nanostructured $\mathrm{CuO}-\mathrm{Cu}$ current collector for which laser ablation and a metal mold are used with respect to the $\mathrm{Cu}$ current collector. The disadvantage of the previous process regarding the application of graphite as the anode material of the $\mathrm{Cu}$ current collector for the conventional battery is the difficulty of large-area applications and a low theoretical capacity. In this study, however, laser ablation over the surface of the $\mathrm{Cu}$ current collector showed that it is possible to directly apply graphite as the anode material through the formation of $\mathrm{CuO}$ with a high theoretical capacity in a fast and simple manner. Furthermore, the laser energy spontaneously generated the nanostructure while oxidized $\mathrm{Cu}$ particles were deposited on the surface of the $\mathrm{Cu}$ current collector, thereby providing the void space to buffer the $\mathrm{CuO}$ volume expansion that occurred during the charging and discharging. In addition, the microstructure was transferred to the $\mathrm{Cu}$ current collector with the laser-ablation nanostructure using the metal mold together with the sinusoidal pathway for the production of the hierarchical structure. This hierarchical structure maximizes the surface area per unit area of the $\mathrm{Cu}$ current collector, thereby leading to an increase in the attraction force between the atoms that then increased adhesion between the $\mathrm{Cu}$ current collector and $\mathrm{CuO}$, resulting in an increased battery capacity. The hierarchically nanostructured $\mathrm{CuO}-\mathrm{Cu}$ current collector presented in this study can be applied directly in the conventional battery-manufacturing processes, and it can also increase the battery capacity and cyclability in an innocuous, chemical-free, quick, and simple manner.

Author Contributions: Conceptualization, W.-G.B.; Formal analysis, J.-Y.S.; Investigation, C.-H.L., J.-E.K., H.-J.K. and J.J.; Writing-Original Draft Preparation, J.-Y.S.; Data Curation, C.-H.L., J.-E.K., H.-J.K. and J.J.; Visualization, C.-H.L., J.-E.K., H.-J.K. and J.J.

Funding: This work was supported from the NRF of Korea by the Grant (NRF-2016R1D1A1B03934431) provided to W.G. Bae.

Conflicts of Interest: The authors declare no conflict no interest.

\section{References}

1. Tarascon, J.-M.; Armand, M. Issues and challenges facing rechargeable lithium batteries. In Materials for Sustainable Energy: A Collection of Peer-Reviewed Research and Review Articles from Nature Publishing Group; World Scientific: Singapore, 2011; pp. 171-179.

2. Sahu, B.; Rincón-Mora, G.A. A low voltage, dynamic, noninverting, synchronous buck-boost converter for portable applications. IEEE Trans. Power Electron. 2004, 19, 443-452. [CrossRef]

3. Lee, H.J.; Lee, S.H.; Ha, K.-S.; Jang, H.C.; Chung, W.-Y.; Kim, J.Y.; Chang, Y.-S.; Yoo, D.H. Ubiquitous healthcare service using zigbee and mobile phone for elderly patients. Int. J. Med. Inform. 2009, 78, $193-198$. [CrossRef] [PubMed]

4. Ohzuku, T.; Iwakoshi, Y.; Sawai, K. Formation of lithium-graphite intercalation compounds in nonaqueous electrolytes and their application as a negative electrode for a lithium ion (shuttlecock) cell. J. Electrochem. Soc. 1993, 140, 2490-2498. [CrossRef]

5. Zhou, M.; Li, X.; Wang, B.; Zhang, Y.; Ning, J.; Xiao, Z.; Zhang, X.; Chang, Y.; Zhi, L. High-performance silicon battery anodes enabled by engineering graphene assemblies. Nano Lett. 2015, 15, 6222-6228. [CrossRef] [PubMed]

6. Wu, H.; Zheng, G.; Liu, N.; Carney, T.J.; Yang, Y.; Cui, Y. Engineering empty space between Si nanoparticles for lithium-ion battery anodes. Nano Lett. 2012, 12, 904-909. [CrossRef] [PubMed]

7. Wang, B.; Li, X.; Qiu, T.; Luo, B.; Ning, J.; Li, J.; Zhang, X.; Liang, M.; Zhi, L. High volumetric capacity silicon-based lithium battery anodes by nanoscale system engineering. Nano Lett. 2013, 13, 5578-5584. [CrossRef] [PubMed]

8. Song, T.; Xia, J.; Lee, J.-H.; Lee, D.H.; Kwon, M.-S.; Choi, J.-M.; Wu, J.; Doo, S.K.; Chang, H.; Park, W.I.; et al. Arrays of sealed silicon nanotubes as anodes for lithium ion batteries. Nano Lett. 2010, 10, 1710-1716. [CrossRef] [PubMed] 
9. Liu, H.; Wang, G.; Wang, J.; Wexler, D. Magnetite/carbon core-shell nanorods as anode materials for lithium-ion batteries. Electrochem. Commun. 2008, 10, 1879-1882. [CrossRef]

10. Park, H.; Lee, S.; Jo, M.; Park, S.; Kwon, K.; Shobana, M.K.; Choe, H. Nanowire-like copper oxide grown on porous copper, a promising anode material for lithium-ion battery. J. Korean Ceram. Soc. 2017, 54, 438-442. [CrossRef]

11. Zhou, X.; Shi, J.; Liu, Y.; Su, Q.; Zhang, J.; Du, G. Microwave-assisted synthesis of hollow $\mathrm{CuO}_{-} \mathrm{Cu}_{2} \mathrm{O}$ nanosphere/graphene composite as anode for lithium-ion battery. J. Alloys Compd. 2014, 615, 390-394. [CrossRef]

12. Zhang, J.; Wang, B.; Zhou, J.; Xia, R.; Chu, Y.; Huang, J. Preparation of advanced CuO nanowires/functionalized graphene composite anode material for lithium ion batteries. Materials 2017, 10, 72. [CrossRef] [PubMed]

13. Wang, X.; Tang, D.-M.; Li, H.; Yi, W.; Zhai, T.; Bando, Y.; Golberg, D. Revealing the conversion mechanism of $\mathrm{CuO}$ nanowires during lithiation-delithiation by in situ transmission electron microscopy. Chem. Commun. 2012, 48, 4812-4814. [CrossRef] [PubMed]

14. Chen, L.B.; Lu, N.; Xu, C.M.; Yu, H.C.; Wang, T.H. Electrochemical performance of polycrystalline CuO nanowires as anode material for li ion batteries. Electrochim. Acta 2009, 54, 4198-4201. [CrossRef]

15. Mai, Y.J.; Wang, X.L.; Xiang, J.Y.; Qiao, Y.Q.; Zhang, D.; Gu, C.D.; Tu, J.P. CuO/graphene composite as anode materials for lithium-ion batteries. Electrochim. Acta 2011, 56, 2306-2311. [CrossRef]

16. Guan, X.; Li, L.; Li, G.; Fu, Z.; Zheng, J.; Yan, T. Hierarchical CuO hollow microspheres: Controlled synthesis for enhanced lithium storage performance. J. Alloys Compd. 2011, 509, 3367-3374. [CrossRef]

17. Cao, F.; Xia, X.H.; Pan, G.X.; Chen, J.; Zhang, Y.J. Construction of carbon nanoflakes shell on CuO nanowires core as enhanced core/shell arrays anode of lithium ion batteries. Electrochim. Acta 2015, 178, 574-579. [CrossRef]

18. Bhushan, B.; Jung, Y.C.; Koch, K. Micro-, nano-and hierarchical structures for superhydrophobicity, self-cleaning and low adhesion. Philos. Trans. A Math. Phys. Eng. Sci. 2009, 367, 1631-1672. [CrossRef] [PubMed]

19. Ho, K.H.; Newman, S.T.; Rahimifard, S.; Allen, R.D. State of the art in wire electrical discharge machining (WEDM). Int. J. Mach. Tools Manu. 2004, 44, 1247-1259. [CrossRef]

20. Cannon, A.H.; King, W.P. Casting metal microstructures from a flexible and reusable mold. J. Micromech. Microeng. 2009, 19, 095016. [CrossRef]

21. Chen, K.; Song, S.; Xue, D. Vapor-phase crystallization route to oxidized $\mathrm{Cu}$ foils in air as anode materials for lithium-ion batteries. CrystEngComm 2013, 15, 144-151. [CrossRef]

22. Unsal, O.; Ayrilmis, N. Variations in compression strength and surface roughness of heat-treated Turkish river red gum (eucalyptus camaldulensis) wood. J. Wood Sci. 2005, 51, 405-409. [CrossRef]

23. Lotfabad, E.M.; Kalisvaart, P.; Cui, K.; Kohandehghan, A.; Kupsta, M.; Olsen, B.; Mitlin, D. Ald TiO 2 coated silicon nanowires for lithium ion battery anodes with enhanced cycling stability and coulombic efficiency. Phys. Chem. Chem. Phys. 2013, 15, 13646-13657. [CrossRef] [PubMed]

(C) 2018 by the authors. Licensee MDPI, Basel, Switzerland. This article is an open access article distributed under the terms and conditions of the Creative Commons Attribution (CC BY) license (http:/ / creativecommons.org/licenses/by/4.0/). 